\title{
Outcome of Pancreatic Anastomosis after Whipple's Operation
}

\author{
Hani Mohamed El Barbary, MD; Mohamed Kandeel Abdel Fattah, MD; \\ Abdel Ghani Mahmoud Elshami, MD; Fateen Abdel-Moneim Anous, MD.
}

\author{
Adapted from the MD Thesis of: \\ Sameh Hamdy Abd El Alim Awad, MB BCh., 2014.
}

\begin{abstract}
Pancreaticoduodenectomy PD (Whipple procedure) remains the procedure of choice for tumors of the periampullary region. However, complications related to the pancreatic remnant, such as pancreatic fistula, anastomotic dehiscence, abscess formation, and septic hemorrhage are the main causes of morbidity and mortality. Some authors have named the pancreatic anastomosis the Achilles heel"of pancreatic surgery because it has the highest rate of surgical complications. Management of the pancreatic remnant after partial pancreaticoduodenectomy is still controversial. The aim of this prospective study was to compare between three different but commonly performed anastomosis namely; end to end pancreaticojejunostomy, end to side pancreaticojejunostomy, and pancreaticogastrostomy after Whipple operation. Thirty patients were the subjects of the present study and were randomly divided into three equal groups: End to end pancreaticojejunostomy (group I), end to side pancreaticojejunostomy (group II) and end to side pancreaticogastrostomy (group III). Our study proved that there was no significant difference as regards leakage after different types of pancreatic anastomosis after Whipple operation. However it was shown that there was a direct link between pancreatic duct size, pancreatic texture and the incidence of pancreatic fistula.
\end{abstract}

\section{Introduction:}

Pancreaticoduodenectomy remains the procedure of choice for tumors of the periampullary region. During the 1980s, many centers reported reduced hospital mortality rates $(<5 \%)$, and some large series from centers with extensive experience in pancreatic resections reported no mortality. However, while resectional surgery for pancreatic cancer has reached a new platform in the last decades and the mortality rates have considerably decreased, the morbidity remains considerable even in centers of excellence. ${ }^{1}$ Critical step in pancreatic surgery is no longer the resection itself but the reconstruction of the pancreaticoenteric anastomosis. Complications related to the pancreatic remnant, such as pancreatic fistula, anastomotic dehiscence, abscess formation, and septic hemorrhage are the main causes of morbidity and mortality following pancreatic head resection. ${ }^{2}$ Some authors have named the pancreatic anastomosis the "Achilles heel" of pancreatic surgery because it has the highest rate of surgical complications. Management of the pancreatic remnant after partial pancreaticoduodenectomy is still controversially discussed. More than 80 different methods of pancreatic reconstruction havebeenproposed, illustrating the complexity of surgical techniques as well as the absence of a gold standard for all patients. Simple closure of the pancreatic duct by ligation, fibrin or tissue glue without performing a pancreatic anastomosis resulted in high rates of fistulas, pancreatitis, and postoperative insulin-dependent diabetes, and therefore has been widely abandoned. 3,4 Surgeons have attempted to lower leak rates by devising a number of anastomotic techniques such as end to end pacreaticojejunostomy versus (vs) end to side pacreatico-jejunostomy, duct to mucosa anastomosis vs dunking anastomosis, pacreaticojejunostomy versus 
pacreatico-gastostomy and the use of internal or external stent. ${ }^{5}$ The use of pharmachological agents that lower the volume of pancreatic exocrine secretion (somatostatin-like analogues) have been tried but the leak rate remains high. ${ }^{6}$ When choosing between the available methods for reconstruction of pancreaticoenteric continuity the issues to be considered are the ease of operation, the incidence of postoperative complications and the long term effect/changes. ${ }^{7}$

\section{Aim of the work:}

Evaluation of the results of different techniques of pancreatic remnant anastomosis in Whipple's procedure including end to end pancreaticojejunostomy, end to side pancreatico-jejunostomy, and pancreaticogastrostomy to find out the risk factors related to postoperative complications namely pancreatic leakage, pancreatic fistula, septic haemorrhage and abscess formation.

This is a prospective study which included 30 patients with resectable carcinoma of the head of the pancreas or periampullary carcinoma who underwent pancreaticoduodenectomy or Whipple's procedure at Ain Shams University Hospitals from June 2009 - March 2012 and included 30 patients. Patients were randomly divided into 3 groups:

Group 1: Patients who underwent pancreatioduodenectomy with end to end pancreaticojejunostomy (PJ).

Group 2: Patients who underwent pancreatioduodenectomy with end to side pancreaticojejunostomy (PJ).

Group 3: Patients who underwent pancreatioduodenectomy with pancreaticogastrostomy (PG).

\section{Inclusion criteria:}

- Age less than/70 years (males or females)

- Resectable periampullary and pancreatic head carcinoma (T1, T2).

- Patients with or without regional lymph node metastasis (No, N1).

- Patients with solitary hepatic focal lesion.

All patients were submitted to full pre-operative work up.

\section{Surgical technique:}

A bilateral subcostal incision was used in all patients. After the abdomen was opened, a search was made for inoperability. Once the decision to resect was made, the operation began by pancreatico-duodenectomy ${ }^{7,8}$ in the following steps:

1. Transection of the midportion of the stomach, anticipating removal of its distal half. The left gastric artery and gastroepiploic arteries were divided, and the gastrocolic omentum was divided down to the pylorus. The mesentery along the lesser curvature of the stomach also was divided to allow reflection of this portion of the stomach and the first portion of the duodenum to the right of the proximal portion of the divided stomach was retracted to the left. The hepatic artery was identified and dissected, removing node-bearing tissue. The right gastric artery was divided at its origin and ligated.

2. The gall bladder was always removed.

3. The common bile duct was transected just above the entrance of the cystic duct.

4. Attention was next directed to the ligament of Treitz, which was divided, and the third and fourth portions of the duodenum were dissected from the posterior abdominal wall. The vessels to the first 1 or 2 inches of the jejunum were. The jejunum was transected between clamps or staples. The proximal end was ligated with umbilical tape, the proximal segment of jejunum and the fourth portion of the duodenum drawn into the right side of the abdomen.

5. The pancreas was divided. The precise point of division depended on the estimated involvement of the gland. Transection was performed at the junction of the neck and body or the mid portion of the body. Dissection then proceeded to free the pancreas from the hepatic artery, dividing and ligating any small tributaries. The neck of the pancreas was retracted towards the right, and the superior mesenteric, splenic, and the portal veins were exposed. The veins draining the head of the pancreas enter on the lateral side of the vein in most instances. Other tributaries that drain 


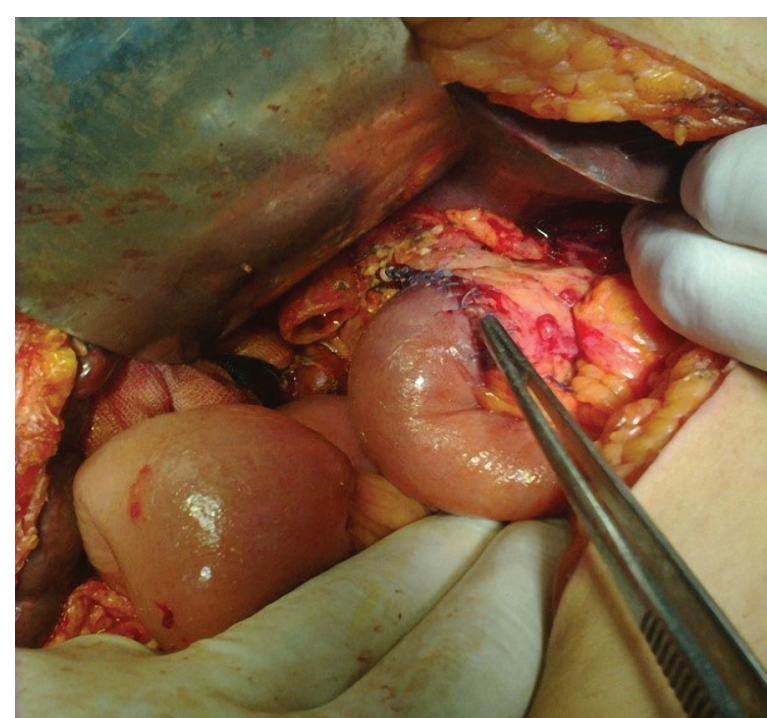

Figure(1): Endto end pancreaticojejunostomy completed.

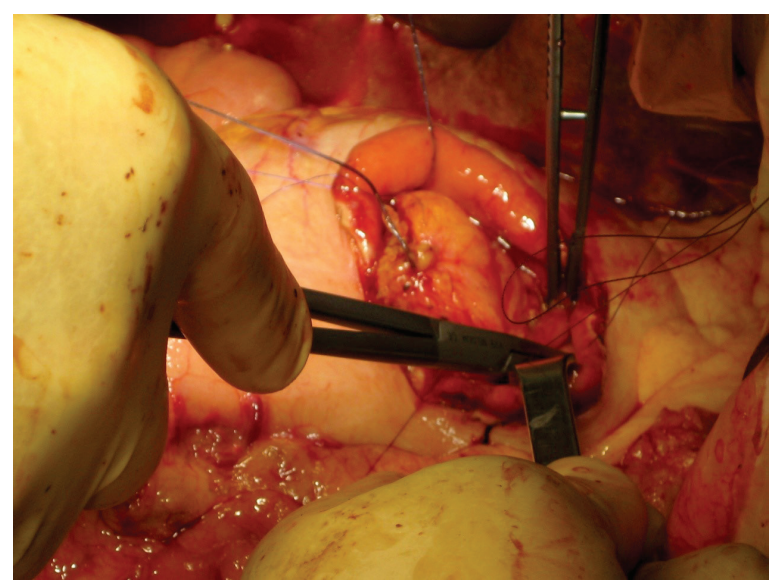

Figure (3): Pancreaticogastrostomy.

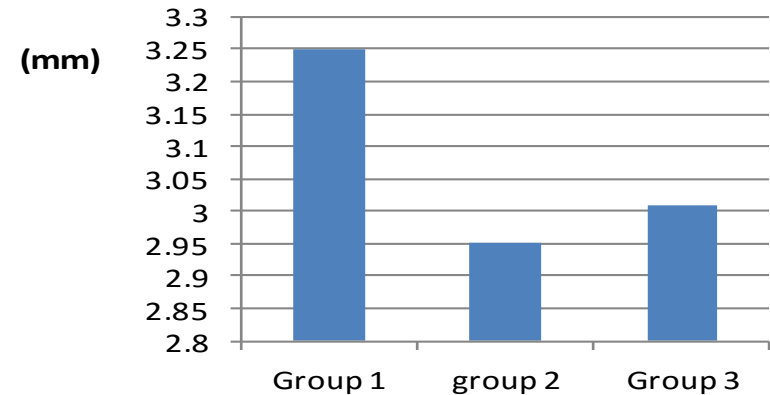

Figure (5): Median diameter of pancreatic duct.

directly from the head of the pancreas and uncinate process into the superior mesenteric or portal veins on the lateral and posterior aspects were treated in a similar manner.

6. Dissection consisted of division of the mesentery of the uncinate process, with individual ligation of the inferior

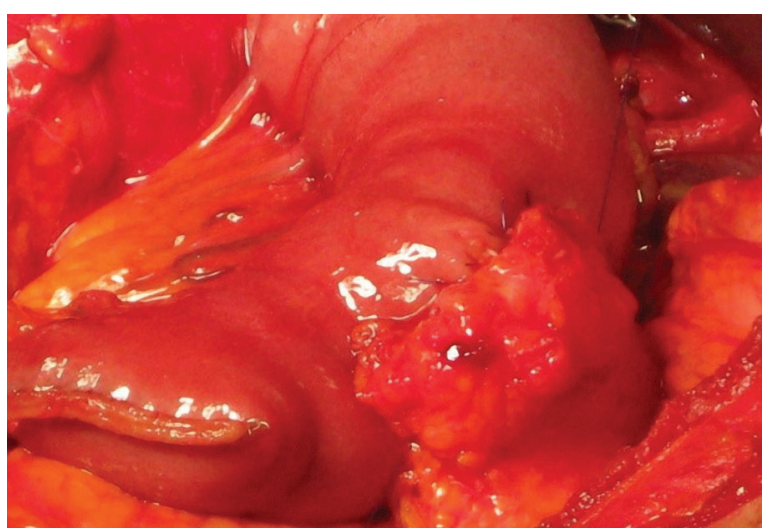

Figure(2): Endtosidepancreaticojejunostomy completed.

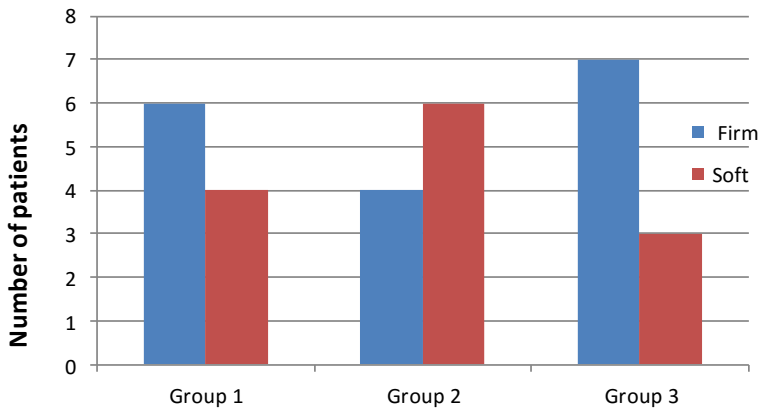

Figure (4): Texture of pancreatic head.

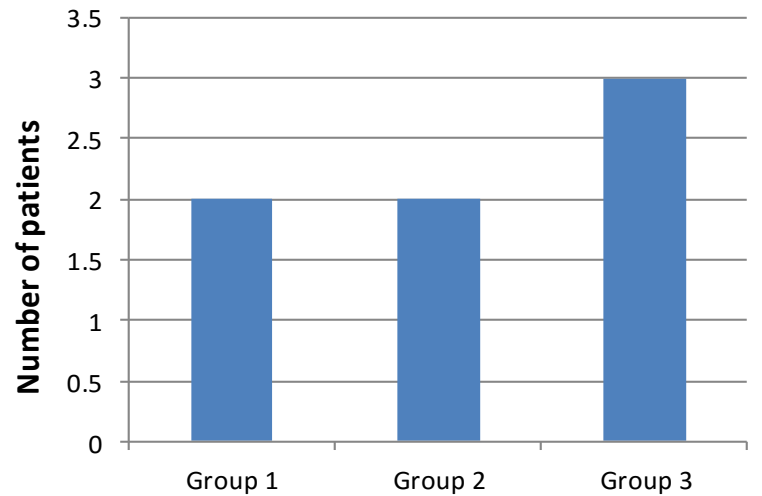

Figure (6): Pancreatic fitula.

pancreaticoduodenal artery. The specimen was now removed and all raw surfaces inspected.

After the specimen was removed, reconstruction of the gastrointestinal continuity was done by three anastomoses:

First anastomosis was between the 


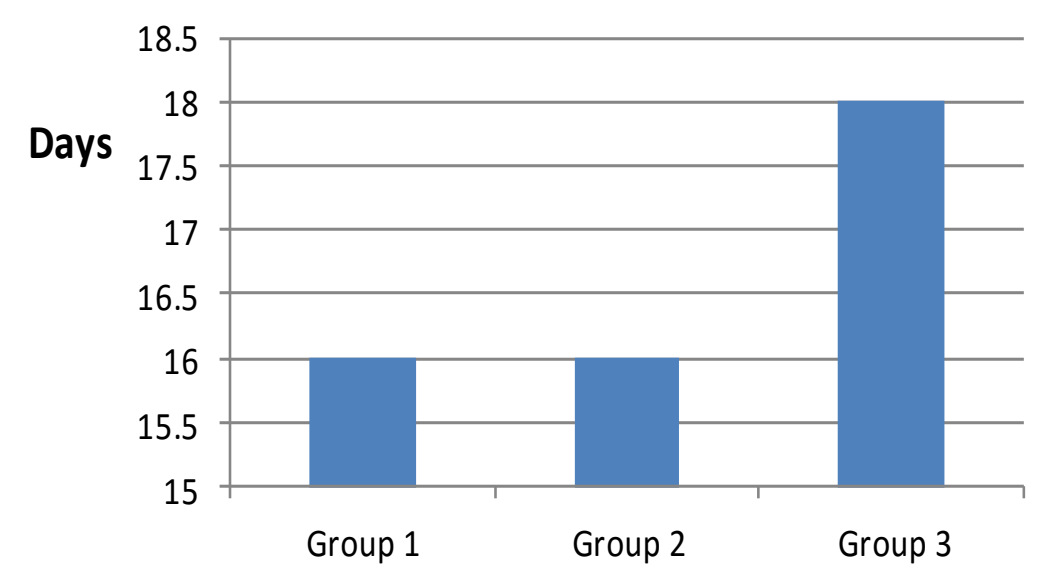

Figure (7): Hospital stay.

Table (1): Comparison between all groups as regard demographic data.

\# Chi-square test.

\begin{tabular}{|c|c|c|c|c|c|}
\hline Variables & $\begin{array}{c}\text { Group } 1 \\
\mathbf{N}=10\end{array}$ & $\begin{array}{c}\text { Group } 2 \\
\mathbf{N}=\mathbf{1 0}\end{array}$ & $\begin{array}{c}\text { Group } 3 \\
\mathbf{N}=10 \\
\end{array}$ & $\mathbf{F}$ & $\mathbf{P}$ \\
\hline Age (yrs) & $58+7$ & $53+6$ & $54.9+6$ & 1.4 & $>0.05 \mathrm{NS}$ \\
\hline $\begin{array}{l}\text { Gender } \\
\text { Male } \\
\text { Female }\end{array}$ & $\begin{array}{l}7(70 \%) \\
3(30 \%)\end{array}$ & $\begin{array}{l}6(60 \%) \\
4(40 \%)\end{array}$ & $\begin{array}{l}6(60 \%) \\
4(40 \%)\end{array}$ & $0.2 \#$ & $\begin{array}{l}>0.05 \\
\mathrm{NS}\end{array}$ \\
\hline
\end{tabular}

Table (2): Comparison between all groups as regard site.

\begin{tabular}{|c|c|c|c|c|c|}
\hline Variables & $\begin{array}{c}\text { Group } 1 \\
N=10\end{array}$ & $\begin{array}{c}\text { Group } 2 \\
N=10\end{array}$ & $\begin{array}{c}\text { Group } 3 \\
\mathbf{N}=10\end{array}$ & $X^{2}$ & $\mathbf{P}$ \\
\hline Cancer head & $6(60 \%)$ & $5(50 \%)$ & $8(80 \%)$ & \multirow[t]{3}{*}{2.9} & \multirow{3}{*}{$\begin{array}{l}>0.05 \\
\text { NS }\end{array}$} \\
\hline Periampullary & $3(30 \%)$ & $3(30 \%)$ & $2(20 \%)$ & & \\
\hline Duodenal carcinoma & $1(10 \%)$ & $2(20 \%)$ & 0 & & \\
\hline
\end{tabular}

Table (3): Comparison between groups as regard pancreatic texture.

\begin{tabular}{|l|l|l|l|l|l|}
\hline Variables & $\begin{array}{c}\text { Group 1 } \\
\mathbf{N}=\mathbf{1 0}\end{array}$ & $\begin{array}{c}\text { Group 2 } \\
\mathbf{N}=\mathbf{1 0}\end{array}$ & $\begin{array}{c}\text { Group 3 } \\
\mathbf{N = 1 0}\end{array}$ & $\mathbf{X}^{\mathbf{2}}$ & \multicolumn{1}{|c|}{ P } \\
\hline Firm & $6(60 \%)$ & $4(40 \%)$ & $7(70 \%)$ & \multirow{2}{*}{1.9} & $\begin{array}{l}>0.05 \\
\mathrm{NS}\end{array}$ \\
\cline { 1 - 4 } Soft & $4(40 \%)$ & $6(60 \%)$ & $3(30 \%)$ & & \multicolumn{2}{|c|}{} \\
\hline
\end{tabular}

Table (4): Comparison between groups as regard duct size.

\begin{tabular}{|l|c|c|c|c|c|}
\hline Variables & $\begin{array}{c}\text { Group 1 } \\
\text { N=10 }\end{array}$ & $\begin{array}{c}\text { Group 2 } \\
\mathbf{N = 1 0}\end{array}$ & $\begin{array}{c}\text { Group 3 } \\
\mathbf{N = 1 0}\end{array}$ & F & P \\
\hline Mean+SD & $2.5+0.6$ & $2.9+0.7$ & $2.4+0.7$ & 0.4 & $>0.05 \mathrm{NS}$ \\
\hline
\end{tabular}

pancreatic stump and the gastrointestinal tract either pancreaticojejunostomy (end to end or end to side) or pancreaticogastrostomy.

1- Pancreaticojejunostomy, end to end:
The jejunum was brought to the region of the pancreas in a retrocolic manner through the region of the ligament of Treitz or in an antecolic position. Reconstruction began 
Table (5): Relation between pancreatic texture versus leakage among 3 groups.

\begin{tabular}{|l|l|l|l|}
\hline \multirow{2}{*}{ Variables } & \multicolumn{2}{|c|}{ Texture } & \multirow{2}{*}{ P } \\
\cline { 2 - 3 } & \multicolumn{1}{|c|}{ Firm } & \multicolumn{1}{c|}{ Soft } & \multirow{2}{*}{} \\
\hline Leakage & $2(11.8 \%)$ & $5(38.4 \%)$ & $<0.05$ \\
\hline No leakage & $15(88.2 \%)$ & $8(61.6 \%)$ & S \\
\hline
\end{tabular}

Table (6): Relation between duct sizes versus leakage among 3 groups.

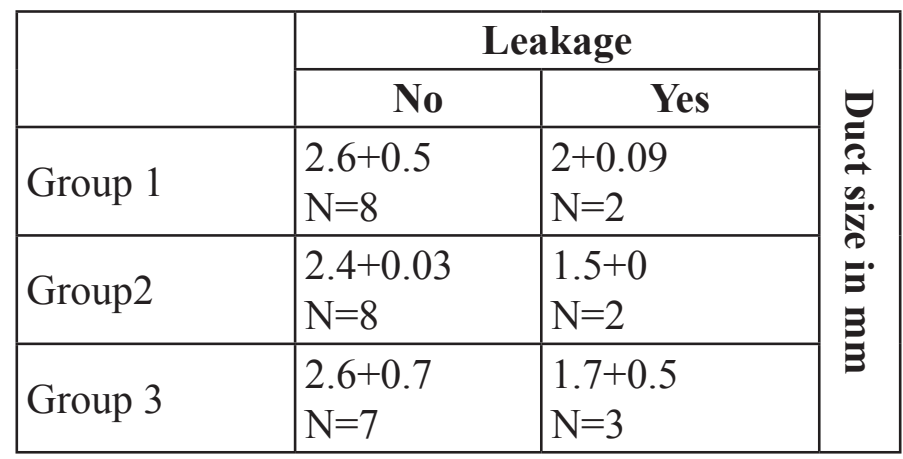

with an end - to - end anastomosis between the pancreas and the jejunum. The pancreas was invaginated into the jejunum, and nonabsorbable sutures were tied to hold the gland in place. Additional sutures were placed to complete the anastomosis. The technique described here, placed the mucosa of the duct in apposition to the mucosa of the jejunum and served the objective well Figure (1).

2- Pancreaticojejunostomy, end to side: The proximal end of the jejunum was closed by $2 / 0$ sutures and an enterostomy done about one inch distal to this end where the pancreatic remnant was anastomosed in 2 layers with an outer non absosrbable suture Figure (2).

3- Pancreaticogastrostomy (end to side) was done by anastomosing the pancreatic remnant to the posterior gastric wall midway between the lesser and greater curvature, at least $7 \mathrm{~cm}$ proximal to the pylorus or distal gastric staple line. The size of the posterior gastrotomy averaged 2.5 to $3 \mathrm{~cm}$. A small incision was made into the stomach opposite the pancreatic remnant by electrocautery and several interrupted 3/0 polypropylene sutures fixed the pancreatic remnant to the full thickness of the stomach wall including the gastric mucosa 0ne or two inches from the stump of the divided pancreas Figure (3).

The second anastomosis was an end -to- side choledochojejunostomy. The distance between the pancreatic and biliary anastomosis would differ according to anatomic relations. We preferred a singlelayer anastomosis using interrupted sutures of 4-0 vicryl or prolene. Before completing the anterior row, a large T-tube was placed in the common hepatic duct.

The third anastomosis was a side - to - side gastrojejunostomy. The distance from the biliary anastomosis to the gastrojejunostomy was 18 inches to prevent reflux of gastric contents to the biliary anastomosis.

Drains were placed in the area of dissection to allow drainage of tissue fluid and lymph. The resected segments were sent to the pathology department for full histopathology examination.

Intraoperative analysis was done for all patients regarding:

A. Type of reconstruction and restoration of GIT continuity after pancreaticoduodenal resection (PG versus PJ

B. Assessment of risk factors related to anastomotic complications e.g.: (texture of pancreas - size of pancreas duct).

\section{Postoperative care:}

All the patients were admitted to ICU (Intensive Care Unit) postoperatively to get careful monitoring of all vital data 
and respiration. Therapeutic antibiotics were administrated for all patients for the first five days in the form of combination of augmentin, garamycin and flagyl. Somatostatin (octreotide) was administrated postoperatively from the 5th day in a dose of $0.5 \mathrm{mcgm}$ subcutaneous every twelve hours till the amount of the drain decrease to less than $50 \mathrm{cc}$ per day. Nasogastric tube was placed for all patients intraoperatively and removed on the 3 rd postoperative day. Feeding was started on the 6th day by fluids and followed by semisolids as tolerated by the patients. Radiological study to exclude leakage was not done routinely for the patients but only for those whose drain amount was more than $150 \mathrm{cc}$ on 10 th day.

All the patients were studied and followed up for 30 days regarding:

A. Pancreatic leakage

B. Pancreatic fistula

C. Intra-abdominal abscess.

Results were tabulated and statistically studied using SPSS ${ }^{\circledR}$ v.16 software:

- Chi square test.

- One-way ANOVA.

Numerical variables were presented as mean and SD or median and range as appropriate, while categorical variables were presented as frequency and percentage. Any difference with $p$ value $<0.05$ was considered statistically significant. Bonferroni's correction of significance level was applied if multiple comparisons were performed.

\section{Results:}

Thirty patients (19 males, 11 females, median age 56 years, range $4269 \rightarrow$ years) were the subjects of the present study.

- 10 patients (7 males, 3 females) median age, 58 years "range 45-69 years" underwent end to end pancreaticojejenostomy (group I).

- $\quad 10$ patients (6 males, 4 females)median age, 56.7 years "44 $65 \rightarrow$ years" underwent end to side pancreaticojejenostomy (group II).

- $\quad 10$ patients ( 6 males, 4 females) median age, 53 years "42- 62 years" underwent end to side pancreaticogastrostomy Table (1).
The main complain was one or more of either weight loss, jaundice or back pain. Abdominal CT showed a mass in the head of the pancreas of variable sizes in 19 patients, periampullary carcinoma in 8 patients and duodenal cancer in 3 patients. ERCP was tried for decreasing serum bilirubin by stenting for 24 patients Table (2).

The median time required for PG (group III) was 5.5 hours (range 5-6h). This was shorter than the median time required for PJ either end to end (group I) or end to side (group II), which was 6.25 hours (range 5.5-7.5h). The difference was statistically significant $(\mathrm{P}<0.001)$. The median amount of blood loss during the operation in $\mathrm{PG}$ group was 630cc (range 400-800cc). This was less than the median blood loss during PJ (either groups), which was 720cc (range $550-1000 \mathrm{cc})$. The difference was statistically significant $(\mathrm{P}<0.05)$. The median amount of units of blood needed for all groups were the same (2 units, range 1-3 units) and this was of no statistical significance. The texture of the pancreatic head as judged by the operating surgeon was firm in 6 patients and soft in 4 patients in group 1; while was firm in 4 patients and soft in 6 patients in group 2 and was firm in 7 patients and soft in 3 patients in group 3 Table (3), Figure (4).

The mean diameter of the pancreatic duct at the transected neck was $2.5 \mathrm{~mm}$ (range: 1.5 $3 \mathrm{~mm}$ ) in group 1; while was $2.95 \mathrm{~mm}$ (range: 2-3.5mm) in group 2 and $2.4 \mathrm{~mm}$ (range: 1.5 $3.5 \mathrm{~mm}$ ) in group 3 Table (4), Figure (5).

Postoperative complications: Six patients in group III developed postoperative complications, three patients developed postoperative complications in group I and four patients in group II.

A. Pancreatic fistula: Three patients in group III developed a pancreatic fistula, which closed spontaneously after three weeks. In group I, two patients developed a pancreatic fistula; one of them closed spontaneously after one month, but the other needed relaporotomy after 15 days for closure of fistula. At relaporotomy, leaked anastomotic line was found with eroded and necrotic edges; so debridement of pancreatic 
and jejunal edges and reanastomosis were done. In group II two patients also developed pancreatic fistula and closed spontaneously after one month Figure (6).

It was accidentally found that; from the seven patients, who developed pancreatic fistula, five patients had a soft pancreatic consistency and five patients had a pancreatic duct less than $2 \mathrm{~mm}$. Four patients had both criteria Table $(\mathbf{5 , 6})$.

This table shows significant difference between both soft and firm texture of pancreas as regard leakage in different groups by using Fisher exact test.

This table shows that cases with pancreatic leakage had a smaller duct size.

B. Other complications: In group I, one patient developed anemic heart failure on $4^{\text {th }}$ day postoperatively, which was controlled by medical treatment and packed red cells transfusion for correction of the anemia. $\mathrm{He}$ bled postoperatively as the drain amount was $>250$ cc bloody for 10 days and decreased gradually with supportive treatment until removed on $16^{\text {th }}$ day. One patient developed wound infection. Frequent dressings and parental antibiotics. In group II, one patient developed cardiovascular complications, in form of deep venous thrombosis on $5^{\text {th }}$ postoperative day and this was controlled by anticoagulants. This patient (10\%) developed also hematemesis on $7^{\text {th }}$ postoperative day. This proved to be secondary to stress ulcer and the anticoagulants, and was controlled by medical treatment and endoscopical injection. One patient developed postoperative pancreatitis and was controlled conservatively and give somatostatin. One patient developed chest complications in the form of chest infection and lung collapse and were controlled by medical treatment and physiotherapy. This patient developed also an intrabdominal abscess, which was drained under ultrasound guidance and under umbrella of antibiotics with good medical control of his high blood sugar level. In group III one patient developed an intrabdominal abscess, which was drained under ultrasound guidance and antibiotics. Another patient developed pneumonia which was controlled by antibiotics. One patient developed diabetic ketoacidosis on third day and was controlled by intravenous fluid correction and insulin. We had four postoperative mortalities, one in group I one in group II and two in group III. The hospital stay in group 1 (median: 16d and range: $14-28 \mathrm{~d}$ ) was nearly equal to that in group 2 (median: 16.6d and range: 12-42d). In group 3 the hospital stays (median: $18 \mathrm{~d}$ and range: 14-40d). The difference was not statistically significant.

The median tumor diameter in group I was $2.5 \mathrm{~cm}$ (range: $1.5-3.5 \mathrm{~cm}$ ), in group II it was $2.55 \mathrm{~cm}$ (range: $2-3.6 \mathrm{~cm}$ ) and $2.2 \mathrm{~cm}$ (range: 1.8-3.4) in group III. Four patients in group I had positive lymph node infiltration, 5 patients in group II had positive lymph node infiltration and 4 patients in group III had positive lymph nodes infiltration. The difference was not statistically significant. One patient (10\%) in PG group had positive marginal infiltration, while 2 patients $(20 \%)$ in PJ group had marginal infiltration. The difference was not statistically significant. In group I, one patient had well-differentiate adeno-carcinoma, 7 patients had moderately differentiated adenocarcinoma and 2 patients had poorly differentiated adenocarcinoma. In group II, one patient had well-differentiated tumor, 6 patients had moderately differentiated tumors and 3 patients had poorly differentiated tumors. In group III two patients had well-differentiated tumor, 6 patients had moderately differentiated tumors and 2 patients had poorly differentiated tumors. The difference was not statistically significant.

\section{Discussion:}

PD is technically difficult, and as a result, relatively high mortality (15\%-30\%) and complication rates (50\%-75\%) were reported before the 1980s. With advances in surgical techniques and perioperative care, the mortality rate associated with PD has since improved to be less than $10 \%$ in best hands. Most complications after PD commonly arise from failure in healing of the pancreatic anastomosis, and have been described as pancreatic fistulas or anastomotic leakages 
by various authors. Berberat et al defined a pancreatic fistula as an anastomotic leak of the pancreatic anastomosis demonstrated radiographically or post-operatively as a prolonged or elevated output of amylaserich fluid through an intraoperatively-placed drain ( $>3$ times the normal serum amylase level). ${ }^{9}$ Lowy et al divided pancreatic fistulas into clinical leakage and biochemical leakage, in which the former referred to the amylase level of the fluid obtained through an intraoperatively-placed drain to be $>3$ times the normal serum amylase level, with a high fever, leukocytosis, sepsis, and the need for drainage, while the latter referred to asymptomatic patients. The definition described by Yeo et al stated that from the $7^{\text {th }}$ postoperative day on, the drain output is $>50$ cc a day and the drain fluid amylase level is 3 times higher than the serum amylase level. ${ }^{10}$

Yeo et al reported that pancreatic fistulas were correlated with anastomotic technique, operative time, a surgeon's skills and experience in performing a PD, tumor location, and co-morbid illnesses. Bartoli et al reported a difference in the degree of fibrosis of the remnant pancreas, and that anastomotic leakage occurred in $5 \%$ of patients with chronic pancreatitis and in $33 \%$ of patients with carcinoma of the CBD. Patients in whom the pancreatic texture has a firm consistency have been reported to be at lower risk for pancreatic leakage than those patients who have a pancreatic parenchyma with a soft or intermediate consistency. ${ }^{6}$ Bassi et al found the incidence of pancreatic fistula to range from $9.9 \%$ to $28.5 \%$ according to the different definitions applied. Pratt et al also reported incidences of pancreatic fistula between $9.1 \%$ and $19.3 \%$ by applying different definitions to 176 patients undergoing a pancreaticoduodenectomy. Arandomized controlled trials revealed no significant difference between $\mathrm{PJ}$ and PG regarding overall postoperative complications, pancreatic fistula, intraabdominal collection or mortality. Although non-randomized observational clinical studies showed significant results in favor of $P G$ in terms of reduction in pancreatic fistula and mortality rate. ${ }^{2}$ The pancreatic duct diameter has also been correlated with pancreatic leakage. Yun et al., 2008 showed that $(20.1 \%)$ of patients had evidence of pancreatic duct dilatation by histopathologic reports, confirming the correlation between pancreatic duct size and pancreatic fistula development. None of the patients with wide pancreatic duct (more than $2 \mathrm{~mm}$ ) developed pancreatic leakage; however, there was no statistical significance. In current study the pancreatic fistula occurred in $23.3 \%$ of patients. This study was conducted to compare the percentage of pancreatic leakage among different types of pancreatic anastomosis (PG, PJ end to end and PJ end to side) and proved no significant difference among any type of anastomosis. However, it was found that $71.4 \%$ of patients ( 5 out of 7 patients) with pancreatic fistula had soft pancreas. Also $71.4 \%$ of patients had a pancreatic duct less than $2 \mathrm{~mm}$, and $57.1 \%$ of patients (4 out of 7 patients) had soft pancreas and narrow duct. The texture of the pancreatic parenchyma has been reported to be correlated with the pancreatic duct diameter, in considering the ease in performing a pancreatic duct-tojejunum mucosa anastomosis; such a simple comparison requires more consideration. The pancreatic duct diameter has also been correlated with pancreatic leakage. Kow et al 2008 stated that overall in-hospital and 30 -day mortality rate of $3 \%$ is comparable to other specialized centers in this region. Poon et al. From HongKong reported a hospital mortality rate of $2.9 \%$ in 140 patients over a 12-year period. In our study we had a higher mortality rate of about $13.3 \%$ in 30 patients. This difference may be due to less number of patients in our study, associated comorbidities and postoperative care. Many high-volume centers reported overall morbidity rate of PD of about $41-50 \%$. In Kow series, 35\% of patients had one or more morbidities and this was again comparable to that reported by Poon et al. From Hong Kong (38.6\%). However, implementation of a standardized management protocol and care pathway has been shown to significantly decrease the rate of mortality. ${ }^{1}$ Our study showed a comparable rate of morbidity, as we had $43.3 \%$ morbidity. 
About $46 \%$ of our morbidities were due to medical problems in the form of pancreatitis, cardiovascular and respiratory affection.

\section{Conclusion:}

Our study proved that there is no significant difference as regard leakage after different types of pancreatic anastomosis. However it was shown that there is a direct link between pancreatic duct size, pancreatic texture and the incidence of pancreatic fistula. In other words, soft pancreatic texture and narrow duct have higher incidence of pancreatic fistula. Other factors affecting pancreatic leakage include operative time, a surgeon's skills and experience in performing a PD, tumor location, and co-morbid illnesses.

\section{Reference:}

1- Ahmad NA, et al: Long term survival after pancreatic resection for pancreatic adenocarcinoma. Am J Gastroenterol 2009; 96: 2609.

2- Bassi C, Falconi M, Salvia R, Mascetta G, Molinari E: Management of complications after pancreatico-duodenectomy in a high volume centre: Results on 150 consecutive patients/with invited commentary. Dig Surg 2001; 18: 453-458.

3- Braasch JW, Gagner M: Pylorus-preserving pancreatoduodenectomy - technical aspects. Langenbecks Arch Chir 1991; 376: 50.

4- Billingsley $\mathrm{KG}$, et al: Outcome after pancreatico-duodenectomy for periampullary cancer: An analysis from the Veterans Affairs National Surgical Quality Improvement
Program. J Gastrointest Surg 2003; 7: 484.

5- Farnell MB, Nagorney DM, Sarr MG: The Mayo clinic approach to the surgical treatment of adenocarcinoma of the pancreas. Surg Clin North Am 2002; 81: 611.

6- Yeo CJ, Cameron JL, Lillemoe KD, Sauter PK, Coleman JA: Does prophylactic octreotide decrease the rates of pancreatic fistula and other complications after pancreaticoduodenectomy? Results of a prospective randomized placebo-controlled trial. Ann Surg 2000; 232: 419.

7- Cameron JL, Pitt HA, Yeo CJ, et al: One hundred and forty-five consecutive pancreatico-duodenectomies without mortality. Ann Surg 2003; 217: 430.

8- Tran KT, Smeenk HG, van Eijck CH, et al: Pyloruspreserving pancreaticoduodenectomy versus standard Whipple procedure: A prospective, randomized, multicenter analysis of 170 patients with pancreatic and periampullary tumors. Ann Surg 2004; 240: 738.

9- Buchler MW, Wagner M, Schmied BM, Uhl W, Friess H: Changes in morbidity after pancreatic resection: Toward the end of completion pancreatectomy. Arch Surg 2003; 138: $1310-1314$.

10- Lowy AM, Lee JE, Pisters P, Davidson BS, Fenoglio CJ: Prospective, randomized trial of octreotide to prevent pancreatic fistula after pancreatico-duodenectomy for malignant disease. Ann Surg 2006; 226: 632.

11- Imaizumi T, Hatori T, Tobita K, Fukuda A, Takasaki K: Pancreaticojejunostomy using duct-to-mucosa anastomosis without a stenting tube. $J$ Hepato-Biliary-Pancreatic Surg 2006; 13: 194-201. 


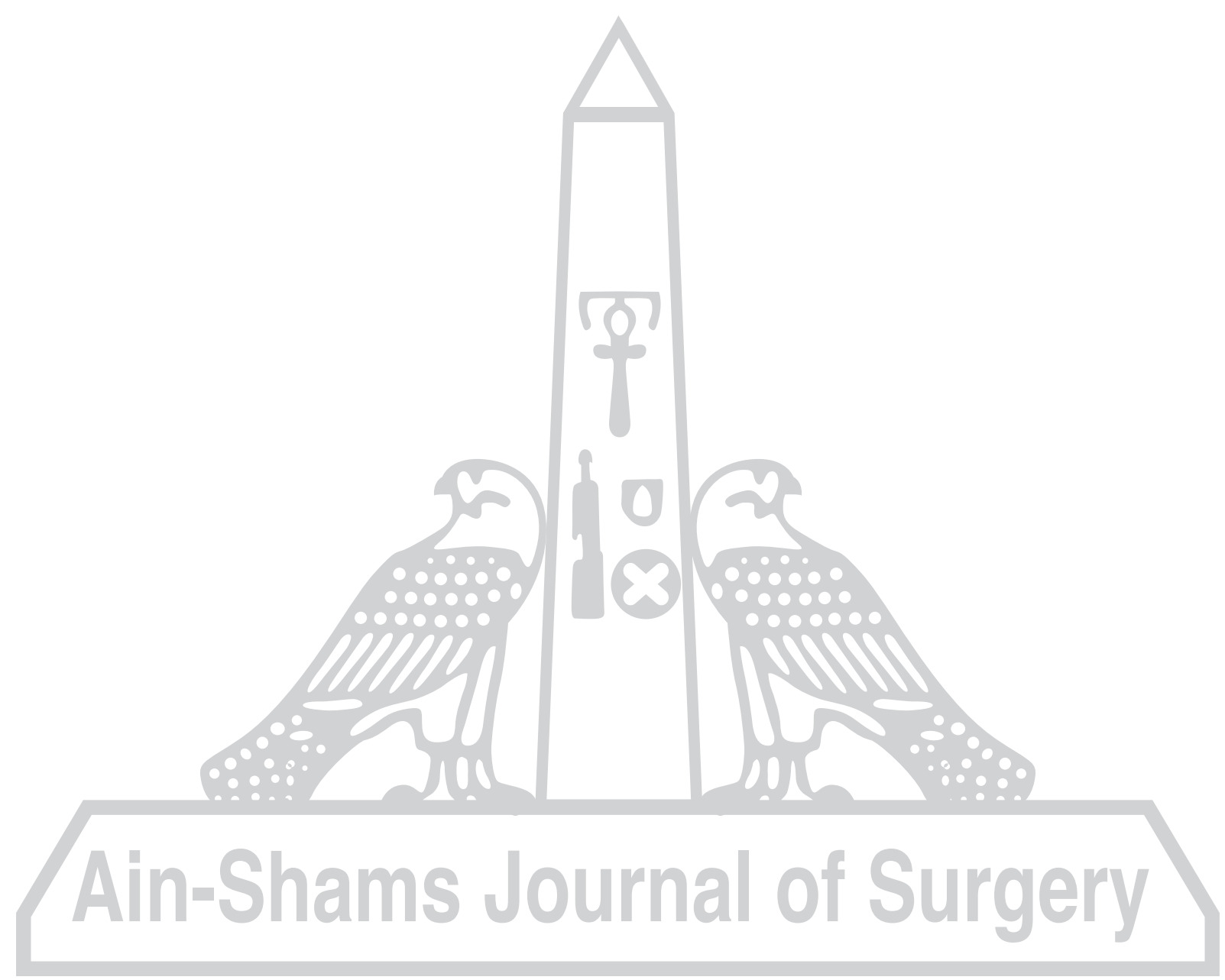

